\title{
CEPHALOMETRIC EVALUATION OF THE CRANIAL BASE IN THE BULGARIAN POPULATION
}

\author{
Katya Todorova-Plachiyska ${ }^{1}$, Silvia Krasteva ${ }^{1}$, Stefan Zlatev ${ }^{2}$, Stilyana Krasteva ${ }^{3}$ \\ ${ }^{1}$ Department of Orthodontics, Faculty of Dental Medicine, Medical University - Plovdiv \\ ${ }^{2}$ Department of Prosthetic Dental Medicine, Faculty of Dental Medicine, \\ Medical University - Plovdiv \\ ${ }^{3}$ Department of Periodontology, Faculty of Dental Medicine, Medical University - Plovdiv
}

\begin{abstract}
INTRODUCTION: The cranial base is a relatively stable area of the craniofacial region used in many radiographic cephalometric analyses. The cephalometric analyses are generally based on the Caucasian cephalometric standards and there has been concern about elaborating the cephalometric analysis to be more specific for the Bulgarian patients.

AIM: The aim of the present study was to determine the cephalometric norms of the cranial bases for the Bulgarian population and to compare them to other standards.

MATERIALS AND METHODS: Lateral cephalograms of 90 orthodontically untreated Bulgarian adults with clinically excellent occlusion were evaluated and the anteroposterior skeletal measurements of the cranial base were assessed using standard cephalometric analyses. The data were processed with statistical package SPSS 19.0.

RESULTS: Based on gender, we established statistically significant differences. The mean values of cranial base indicators did not differ between subjects of different age in the sample.

CONCLUSION: The mean values for the total sample can be used as cephalometric standards for Bulgarians. Cephalometric values identified for Bulgarian subjects are expected to help in the simplification of orthodontic diagnoses.
\end{abstract}

Keywords: Bulgarian population, cranial base, cephalometric assessment

Address for correspondence:

Katya Todorova-Plachiyska

Faculty of Dental Medicine

Medical University - Plovdiv

3 Hristo Botev Blvd

4000 Plovdiv

e-mail:dr.katya.todorova@gmail.com

Received: January 12, 2017

Accepted: June 29, 2017

\section{INTRODUCTION}

The cranial base is the most complex structure of the human skeleton and its main function is to protect and support the brain. The cranial base is the first region of the skull which reaches adult size and it is the structural foundation of many aspects of the craniofacial architecture $(1,2)$. The basicranium connects with the rest of the body, articulates with the vertebral column and the mandible, provides con- 
Cephalometric Evaluation of the Cranial Base in the Bulgarian Population

duits for all the vital neural and circulatory connections between the brain and the face and neck, houses and connects the sense organs in the skull and forms the roof of the nasopharynx $(3,4)$. The skeletal architecture of the cranial base is therefore a multifactorial product of numerous phylogenetic, developmental and functional interactions.

The cranial base has been the subject of numerous studies $(5,6,7,8)$. It is a special interest region in orthodontics, once its growth and development are related to the face, directly influencing the growth of the maxilla and mandible and, consequently, the establishment of their anteroposterior relationship. The cranial base is composed of different bones (sphenoid, ethmoid, frontal, parietal, temporal, and occipital) interconnected by synchondrosis (5). It can be divided into anterior cranial base (Sella - Nasion) and total cranial base (Basion - Nasion). The Sella Nasion plane has been found to be a useful tool for cephalometric evaluation, because the maxilla seems to grow forward at an almost identical rate with Nasion (7). The Basion - Nasion plane represents a line of separation of the face from its supporting superstructure. It crosses the base of the pterygoid plates and the horizontal alae of the great wings of the sphenoid at the floor of the middle cranial fossa. As a basic plane for the study of growth behaviour of both the chin and the maxilla, the Basion - Nasion plane offers distinct advantages over Sella - Nasion plane (8).

It has been suggested, however, that assessment of the cranial bases (Basion - Nasion and Sella - Nasion) might have diagnostic and prognostic potential. The studies indicate that linear skeletal bases for a given population improve the accuracy of research and diagnostic processes (9). Cranial base features for different ethnic and racial groups have been established previously in many studies $(10,11,12,13)$. Therefore, studies involving cephalometric standards of European-American, African-American, Japanese, and Chinese populations, have been published but little has been mentioned about the Bulgarian population. Most researchers have concluded that there are significant differences among these groups and many cranial base standards have been developed for the different groups. These studies indicate that normal measurements for each group should not be considered normal for each race or ethnic group. As a result, the purpose of the present study was to define the skeletal features of the skull bases of Bulgarian adults.

\section{MATERIALS AND METHODS}

Ninety subjects were enrolled in the study after 390 adult Bulgarians were examined. The 90 cases were chosen according to the following criteria: Class I dental and skeletal malocclusion who presented Class I molar relationship with normal overjet and overbite and no history of orthodontic treatment. Lateral cephalometric radiographs with the Nasion support and millimetre ruler visible in the radiograph were conducted for this study. Facial form and postural head position were correlated by using the Frankfort Horizontal Plane as the plane of orientation. This study was approved by the institutional Ethics in Human Research Committee (protocol P2106 /2014).

Lateral head films of these 90 subjects were traced and analysed. A combination of already known methods of Jacobson (14) and Ricketts (15) was used for the cephalometric analysis. Cephalometric tracings were performed on standard acetate paper with a $0.3 \mathrm{~mm}$ graphite mechanical pencil, transparent ruler to the nearest $0.5 \mathrm{~mm}$, and protractor to the nearest $0.1^{\circ}$. All assessments were performed by the same investigator in a darkened room with a radiographic illuminator to ensure contrast enhancement of landmarks. The films were traced and subsequently measured twice by hand. The two tracing procedures were carried out by the same orthodontist who performed all the measurements in order to avoid calibration problems. The following cephalometric landmarks were plotted on each patient's lateral head film (Fig.1):

The following reference cephalometric planes and skeletal measurements were chosen to demonstrate the basic skeletal characteristics of the subjects: 1) Sella - Nasion $(S-N)$ plane that represents the anterior cranial base, 2) Basion - Nasion $(\mathrm{Ba}-\mathrm{N})$ plane that represents the total cranial base, 3) ANB - angular indicator for assessment of the sagittal relationship between the jaws; 4) WITS - linear indicator for assessment of the relationship between the jaws.

Data were processed with statistical package SPSS 19.0 (IBM Corp. 2010) (16). For the level of significance, in rejecting the null hypothesis, $\mathrm{p}<0.05$ was chosen. The data are normally distributed and 
Katya Todorova-Plachiyska, Silvia Krasteva, Stefan Zlatev et al.

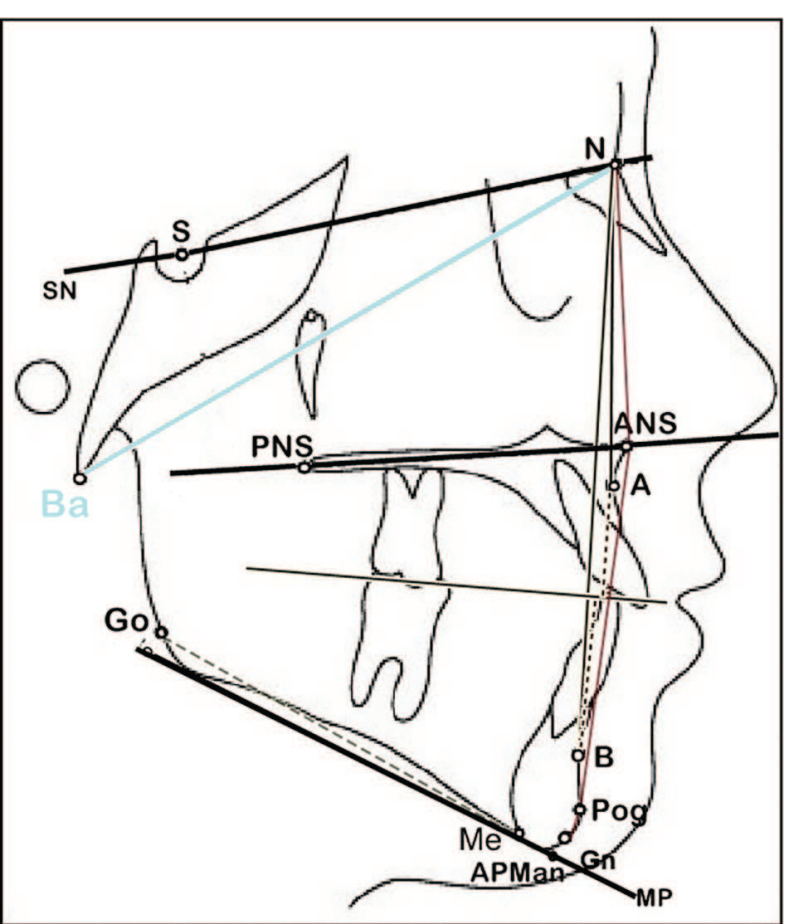

Figure 1. Cephalometric landmarks: Sella (S) - the centre of sella turcica, Nasion $(N)$ - the most anterior limit of suture nasofrontal, Basion (Ba) - the median point of the anterior margin of the foramen magnum located by following the image of the slope of the inferior border of the basilar part of the occipital bone to its posterior limit, Point A (A) - the deepest point on the contour of the alveolar projection, between the spinal point and prosthion; point $B(B)$ - the deepest midline point on the mandible between infradentale and pogonion.

in this case for testing the hypothesis of presence of a statistically significant difference based on the gender the independent samples t-test was used.

\section{RESULTS}

The gender diversity in our sample was 44 men and 46 women. The average age of the total sample was $22.4 \pm 0.26$ years. The Kolmogorov-Smirnov test was applied to the data and it showed that the data were normally distributed.
Table 1 shows the mean values, standard deviations, maximum and minimum values of cephalometric indicators for each parameter of the 90 Bulgarian subjects with completed growth and normal sagittal relationships.

The mean value of angle ANB is $2.39 \pm 0.11^{\circ}$ and for the WITS appraisal $(\mathrm{AO}-\mathrm{BO})$ it is $0.98 \pm 0.19$ $\mathrm{mm}$. Measurements confirm that the monitored subjects are with normal sagittal relationships of both jaws (skeletal class I) and can be used as a cephalometric standard for the Bulgarian population.

The mean value of the total base of the skull $\mathrm{Ba}$ - $\mathrm{N}$ for the Bulgarian population is $111.30 \pm 0.63 \mathrm{~mm}$ and for the anterior cranial base $\mathrm{S}-\mathrm{N}$ is $72.80 \pm 0.43$ $\mathrm{mm}$.

The distribution of cephalometric indicators in the group of adult Bulgarians of 19 to 26 years of age shows that average indicators and their standard deviations are overlapping significantly (Table 2 ).

The mean values of total basicranial length ( $\mathrm{Ba}-$ sion - Nasion) and anterior basicranial length (Sella Nasion) do not differ between age groups, which can be seen in Fig. 2 and Fig. 3. Since reliability was found

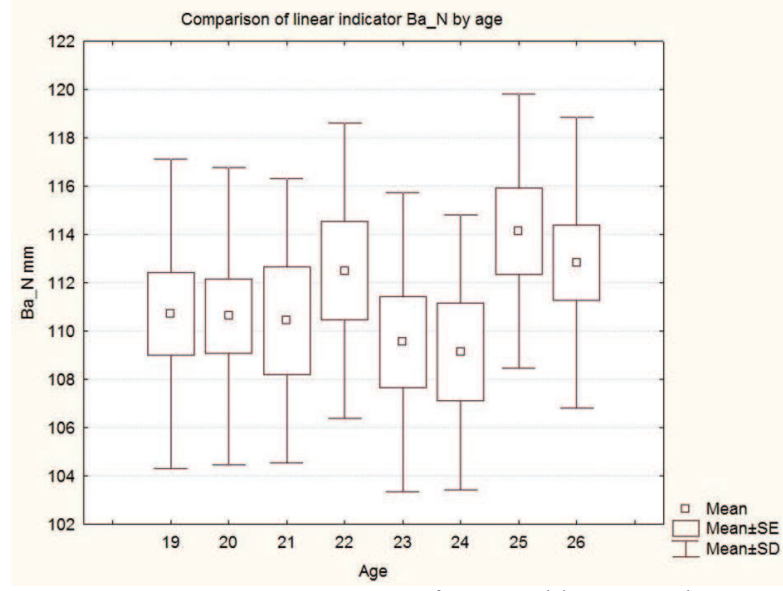

Fig. 2. Descriptive statistics of age and linear indicator $\mathrm{Ba}-\mathrm{N}$

Table 1. Cephalometric norms for the Bulgarian population $(n=90)$

\begin{tabular}{lcccc}
\hline Cephalometric indicators & Min & Max & mean \pm SE & $95 \% \mathrm{CI}$ \\
\hline ANB $^{\circ}$ & 0 & 4 & $2.39 \pm 0.11$ & {$[2.19 ; 2.62]$} \\
$\mathrm{AO}-\mathrm{BO} \mathrm{mm}$ & 1 & 4 & $0.98 \pm 0.19$ & {$[0.59 ; 1.36]$} \\
$\mathrm{S}-\mathrm{N} \mathrm{mm}$ & 64 & 82 & $72.80 \pm 0.43$ & {$[71.94 ; 73.67]$} \\
$\mathrm{Ba}-\mathrm{N} \mathrm{mm}$ & 101 & 124 & $111.30 \pm 0.63$ & {$[110.04 ; 112.57]$} \\
\hline
\end{tabular}


Cephalometric Evaluation of the Cranial Base in the Bulgarian Population

Table 2. Distribution of cranial base indicators by age in the group of adult Bulgarians

\begin{tabular}{lcccccc}
\hline Cephalometric indicator & Age & N & $\begin{array}{c}\text { Mean values } \\
(\mathrm{mm})\end{array}$ & SE & Min & Max \\
& 19 & 14 & 1107143 & 171188 & 1070160 & 1144126 \\
& 20 & 16 & 1106250 & 153603 & 1073510 & 1138990 \\
& 21 & 7 & 1104286 & 222387 & 1049870 & 1158702 \\
& 22 & 9 & 1125000 & 204124 & 1077929 & 1172071 \\
Ba-N & 11 & 1095455 & 187017 & 1053785 & 1137124 \\
& 23 & 8 & 1091250 & 201501 & 1043603 & 1138897 \\
& 25 & 10 & 1141500 & 179513 & 1100891 & 1182109 \\
& 26 & 15 & 1128333 & 155584 & 1094964 & 1161703 \\
& total & 90 & 1113056 &, 63564 & 1100426 & 1125686 \\
& 19 & 14 & 729286 & 133821 & 700375 & 758196 \\
& 20 & 16 & 733125 & 100195 & 711769 & 754481 \\
& 21 & 7 & 707857 &, 97503 & 683999 & 731715 \\
S-N & 9 & 725556 &, 99807 & 702540 & 748571 \\
& 22 & 11 & 719545 & 114902 & 693944 & 745147 \\
& 23 & 8 & 728125 & 151462 & 692310 & 763940 \\
& 24 & 10 & 737500 & 144193 & 704881 & 770119 \\
& 26 & 15 & 732333 & 124963 & 705531 & 759135 \\
& total & 90 & 728056 &, 43567 & 719399 & 736712 \\
\hline \hline
\end{tabular}

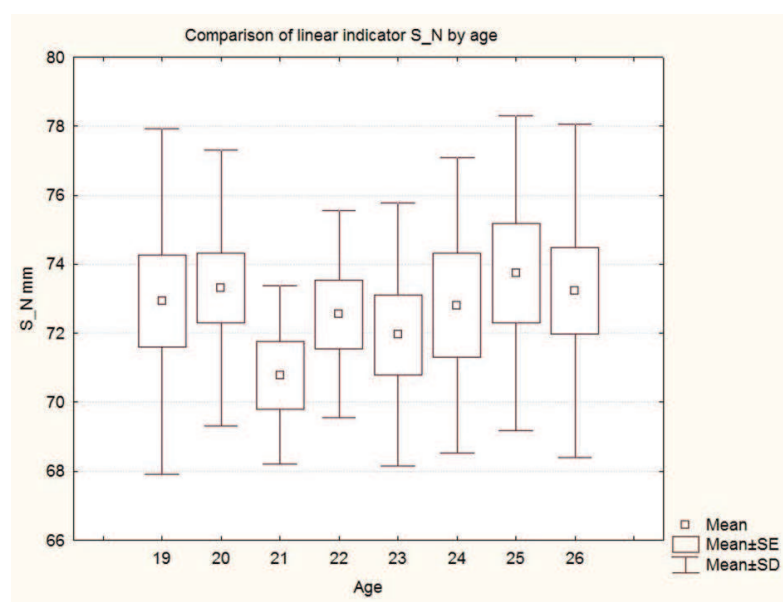

Fig. 3. Descriptive statistics of age and linear indicator

$$
S-N
$$

to be satisfactory, the average values of the measurements can be used as a standard for the subjects.

Based on the gender we have established statistically significant differences according to Athanasiou (15). The data presented in Table 3 include average values and the standard deviation in the Bulgarian sample compared to different standards. Large varia- tion was found comparing our findings and the standards of Bell, Proffit and White (15).

The gender dimorphism was found to be statistically significant for the studied cephalometric variables. Cranial base measurements were significantly greater in Bulgarian males than in females. The observed mean value of the anterior cranial base for Bulgarian males was $75.43 \mathrm{~mm}$, with a standard deviation of $0.52 \mathrm{~mm}$. In our female group, the anterior basicranial length showed mean value of 70.29 $\mathrm{mm}$, with a standard deviation of $0.44 \mathrm{~mm}$. In the female group, the mean value for total cranial base length was once again reduced compared to males and showed statistically significant difference, being $108.06 \mathrm{~mm}$, with a standard deviation of $0.74 \mathrm{~mm}$.

\section{DISCUSSION}

The human skull, especially its base, has always aroused the interest of many scientists, such as anthropologists and orthodontists. Current orthodontics is no longer restricted to dental arches and their occlusion. Its constant evolution has enabled a better understanding of the craniofacial growth and devel- 
Katya Todorova-Plachiyska, Silvia Krasteva, Stefan Zlatev et al.

Table 3. Comparison of Bulgarian norms with other standards

\begin{tabular}{|c|c|c|c|c|c|c|c|c|}
\hline $\begin{array}{l}\text { Cranial base } \\
\text { indicators }\end{array}$ & Gender & Bulgarians & $\mathrm{T}$ & $\mathrm{P}$ & $\begin{array}{l}\text { Bell, Proffit } \\
\text { and White } \\
(16)\end{array}$ & Jarabak & Schwarz & Clark \\
\hline \multirow{2}{*}{$\mathrm{S}-\mathrm{N} \mathrm{mm}$} & Male & $75.43 \pm 0.52$ & \multirow{2}{*}{7.51} & \multirow{2}{*}{$0.0001^{*}$} & $83 \pm 4$ & $78 \pm 3$ & \multirow{2}{*}{72.32} & \multirow{2}{*}{$74 \pm 3.3$} \\
\hline & Female & $70.29 \pm 0.44$ & & & $71 \pm 4$ & $71 \pm 3$ & & \\
\hline \multirow{2}{*}{$\mathrm{Ba}-\mathrm{N} \mathrm{mm}$} & Male & $114.69 \pm 0.76$ & \multirow{2}{*}{6.22} & \multirow{2}{*}{$0.0001^{\star}$} & $120 \pm 4$ & $118 \pm 5$ & \multirow{2}{*}{-} & \multirow{2}{*}{$115 \pm 4.5$} \\
\hline & Female & $108.06 \pm 0.74$ & & & $112 \pm 5$ & $112 \pm 3$ & & \\
\hline
\end{tabular}

opment, thus obtaining an integrated view of the cranium, face, TMJ and dental occlusion.

Bulgarian researches (17-22) have emphasised the influence of understanding the integration of the craniofacial skeleton variants, and indicated that, when evaluating individual craniofacial skeletal patterns, a greater perspective on the etiology of malocclusions is observed. When considering the relationship of the cranial base with the dentofacial complex, conclusions suggest that the factors combination is complex, with a great array of adjustments, and the integration of these factors determines the facial harmony or disharmony. It is important to take into consideration the variations in soft tissue indicators and individual differences in reference to orthodontic, orthopaedic and orthodontic-surgical changes.

Based on our results, the mean values of the total sample can be used as cephalometric standards for Bulgarians. The cephalometric guidelines for the different ethnic and racial groups established in various studies $(5,12-15)$ show that normal measurements for one group are not necessarily normal for another group, which means that each racial group must be treated according to its own characteristics.

The results in our study confirm previous research on the gender dimorphism presented in specialised literature. This is in accordance with Langlade (23) and Bishara (24) who found larger linear dimensions in male subjects. The cephalometric mean values recorded for the Bulgarian population were similar to Jarabak's standards (25). The presented disagreements (Table 3 ) between our findings and the norms of Bell, Proffit and White (15), Schwartz (26) and other researches $(12,13)$ might be due to the racial differences and case selection procedures (i.e. age, number of subjects). In our study, the cases were Bulgarian adults with Bulgarian cephalometric norms. Each person has a unique facial architecture.
Therefore, the study of one variable alone is not sufficient to understand the characteristics of a facial type. However, the orthodontist should not forget that in some cases the causative morphological factor of a disharmonic facial pattern can also result from alterations present in the cranial base, and not only from a linear disproportion between the structures of the jaws.

\section{CONCLUSIONS}

Linear measurements for the assessment of the cranial base dimensions were evaluated according to both anterior cranial base length $(\mathrm{S}-\mathrm{N})$ and total cranial base length $(\mathrm{Ba}-\mathrm{N})$. The results in our study demonstrated statistically significant differences between males and females according to cranial base measurements and confirmed previous research about gender dimorphism presented in specialised literature. The mean values for the total sample can be used as cephalometric standards for Bulgarians. This study would be very useful for growth forecast, prognostic and treatment planning in growing patients.

With the current analysis we can conclude that the Ba-N indicator shows reliable results in the sphere of morphology and is therefore beneficial tool for prediction of orthodontic treatment.

\section{REFRENCES}

1. Ford EHR. Growth of the human cranial base. Am J Orthod. 1958; 44(7):498-506. doi: 10.1016/0002-9416(58)90082-4

2. Wolff K, Hadadi E, Vas Z. A novel multidisciplinary approach toward a better understanding of cranial suture closure: The first evidence of genetic effects in adulthood. Am J Hum Biol. 2013; 25(6): 835-43. doi: 10.1002/ajhb. 22459. 
3. Enlow D, Hunter W. The growth of the face in relation to the cranial base. Rep Congr Eur Orthod Soc. 1968; 44:321-35.

4. Mutafchiev V, Krumova V, Jordanov V. Orthodontics. Sofia:Nemizida, 2003. (in Bulgarian)

5. Cameron N, Bogin B. Human growth and development. Elsevier Inc.; 2012.

6. Graber T, Vanarsdall LR, Vig K. Orthodontics: Current Principles and Techniques. Elsevier Mosby; 2005.

7. Rakosi T. An atlas and manual of cephalometric radiography. $1^{\text {st }}$ Ed. United States, St. Louis, Missouri: Mosby; 1982.

8. Ricketts RE. New perspectives on orientation and their benefits to clinical orthodontics - part I. Angle Orthod. 1975; 45(4):238-48.

9. Downs W. Variation in facial relationships: their significance in treatment and prognosis. Am J Orthod. 1949; 34(10):812-40. doi: 10.1016/0002-9416(48)90015-3

10. Lieberman DE. The evolution of the human head. Cambridge, MA: Belknap (Harvard University) Press; 2011.

11. Sardi ML, Ramírez Rozzi FV. Different cranial ontogeny in Europeans and Southern Africans. PLoS One. 2012; 7(4): 35917. doi: 10.1371/ journal.pone 0035917

12. Miyajima $K$, McNamara JA, Kimura T, Murata $S$, Iizuka T. Craniofacial structure of Japanese and European-American adults with normal occlusions and well-balanced faces. Am J Orthod Dentofacial Orthop. 1996; 110(4):431-8. doi: 10.1016/ S0889-5406(96)70047-1

13. Basciftci FA, Uysal T, Buyukerkmen A. Craniofacial structure of Anatolian Turkish adults with normal occlusions and well balanced faces. Am J Orthod Dentofacial Orthop. 2004; 125(3):366-72. doi: $10.1016 /$ S0889540603008928

14. Jacobson A. Radiographic Cephalometry. From basics to 3-D imaging. $2^{\text {nd }}$ Ed. Quintessence Publishing Co.; 2006.

15. Athanasiou AE. Orthodontic Cephalometry, Mosby - Wolfe. 1995; 190 - 197, 265 - 279.

16. IBM Corp. Released 2010. IBM SPSS Statistics for Windows, Version 19.0. Armonk, NY: IBM Corp.

17. Krusteva S. Transverse deviation of occlusion and facial asymmetry - models for diagnostic assess- ment [PhD Thesis]. Plovdiv: Medical University of Plovdiv; 2011. (in Bulgarian)

18. Petrunov V. Epidemiological study of malocclusions and orthodontic treatment need in Bulgarians in the period from mixed to permanent dentition [PhD Thesis]. Sofia: Medical University of Sofia; 2012. (in Bulgarian)

19. Krumova V, Petrunov V. Cephalometric study of adult Bulgarians with normal occlusion and harmonious face. Orthodontic review. 2000; 2(2): 3-9. (in Bulgarian)

20. Jordanova M. Diagnostichno prouchvane na suotnoshenijata na tvurdite i meki tukani na liceviq profil [PhD Thesis]. Plovdiv: Medical University of Plovdiv; 2007. (in Bulgarian)

21. Jordanova S. Izsledvane na apikalnata baza - diagnostichna ocenka [PhD Thesis]. Plovdiv: Medical University of Plovdiv; 2010. (in Bulgarian)

22. Gurgurieva V. Morphometric analysis of soft tissue facial profile [PhD Thesis]. Sofia: Medical University of Sofia; 2013. (in Bulgarian)

23. Langlade M. Diagnostic orthodontique. $2^{\text {nd }}$ Ed. Maloine; 1981.

24. Bishara SA. Textbook of orthodontics. Philadelphia, Pennsylvania, U.S.A.: W.B. Saunders Co, 2001.

25. Chateau M. Orthopedie Dento-Faciale. Tome 1, Editions CdP. 1998.

26. Schwartz H. A Method of measuring points in spaces recorded by the Broadbent-Bolton cephalometric technique. United States, Evanston, Illinois: North Western University; 1943. 